\title{
Removal of phenols from aqueous solutions with solvating extractants
}

\author{
Magdalena Regel-Rosocka, Maciej Wiśniewski \\ Poznan University of Technology, Institute of Chemical Engineering and Technology, pl. M. Skłodowskiej-Curie 2, \\ 60-965 Poznan, Poland, e-mail: magdalena.regel-rosocka@put.poznan.pl
}

\begin{abstract}
The removal of selected phenols (phenol, 4-methoxyphenol, 4-fluorophenol, 4-nitrophenol, 4-methylphenol, 4-chlorophenol, 2,4-dichlorophenol) from aqueous streams by liquid-liquid extraction is studied. Butylene and propylene carbonate - are used as green extractants. They permit to remove almost $100 \%$ of the examined phenols from feed solutions of phenol concentration about $20 \mathrm{~g} / \mathrm{dm}^{3}$. Additionally, stripping of phenols from loaded organic phases is carried out with $\mathrm{NaOH}$. The results of extraction parameters for alkylene carbonates (extraction efficency and distribution ratio) are compared with commercial solvating extractant - Cyanex 923.
\end{abstract}

Keywords: extraction, stripping, phenols, Cyanex 923, alkylene carbonates, solvating extractants.

\section{INTRODUCTION}

Phenols in wastewaters are considered as harmful and toxic for surface water, particularly for tap water. They are listed in the 76/464/EEC Directive of the European Union, related to hazardous substances discharged into the aquatic environment. Phenols cause nasty smell and taste of water even at low concentrations, e.g., chlorophenols are perceptible in the $0.5-1 \cdot 10^{-6} \mathrm{~g} / \mathrm{dm}^{3}$ concentration range. Phenols cumulate in the meet of fish, and are responsible for its nasty taste. Additionally, as they are easily oxidized their presence in small reservoirs can disturb oxygen equilibrium there. Removal of phenols is a key issue for the industry producing phenolic wastewaters not only due to environmental protection but also the recovery of the chemical materials.

Adsorption using activated charcoal ${ }^{1}$, modified bentonite $^{2}$, polymeric resins and many others ${ }^{3}$ are the methods most frequently applied for the removal of phenols. Among the various methods membrane techniques ${ }^{4-6}$ and liquid-liquid extraction ${ }^{5,7,8}$ are also often used for the purification of phenolic wastewaters.

Alkylene carbonates are formed in the reaction of alkylene oxide with carbon dioxide over a catalyst. Alkylene carbonates are easily biodegradable in the environment because they have functional groups that are susceptible to hydrolysis ${ }^{9},{ }^{10}$. They are not classified as dangerous or toxic substances according to the 2001/59/ EC Directive of the EU. Due to their environmental friendly features, the authors have decided to use alkylene carbonates in the extraction of dyes ${ }^{\mathbf{1 1}}$, and now for the removal of phenols.

It is the aim of this work to study the application of butylene and propylene carbonates for phenol, 4-methoxyphenol, 4-fluorophenol, 4-nitrophenol, 4-methylphenol, 4-chlorophenol and 2,4-dichlorophenol extraction from aqueous solutions and compare their extractive properties with commercial solvating extractant Cyanex 923.

\section{EXPERIMENTAL}

1,2-butylene carbonate (JEFFSOL BC, Huntsman, USA), propylene carbonate (ICSO, Kędzierzyn-Koźle) and trialkylphospine oxides known as Cyanex 923 (Cytec Industries Inc., Canada) were used as extractants. The struc- tures of the applied extractants are presented in Fig. 1. Cyanex 923 is a mixture of four trialkylphosphine oxides, where R states for normal octyl or hexyl group ${ }^{12}$. BC and PC were used without the diluent, and Cyanex 923 was diluted in octane or toluene $(0.1 \mathrm{M})$.

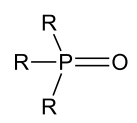

Cyanex 923

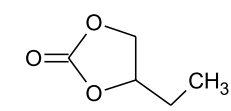

Butylene carbonate (BC)

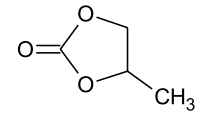

$\mathrm{H}_{3}$
Figure 1. Structures of the extractants used

Aqueous feeds contained $0.01-22 \mathrm{~g} / \mathrm{dm}^{3}$ of phenol, 4-methoxyphenol, 4-fluorophenol, 4-nitrophenol, 4-methylphenol, 4-chlorophenol, or 2,4-dichlorophenol. All the chemicals were used as received. Concentrations of phenols in the aqueous phase were determined at 270, 295, 277, 217, 317, 280 and $286 \mathrm{~nm}$, respectively, with a spectrophotometer Specord 40 (Analytik Jena, Germany).

The extraction was carried out in a typical way at $20^{\circ} \mathrm{C}$. Equal volumes of both phases $\left(5 \mathrm{~cm}^{3}\right)$ were mechanically shaken in separatory funnels, then left to stand for separation. The aqueous phase was analyzed for phenol content, and the organic phase was taken for stripping. $0.1 \mathrm{M}$ $\mathrm{NaOH}$ was used as a strippant. Water content in the organic phase after the extraction was determined by KarlFischer titration.

\section{RESULTS AND DISCUSSION}

\section{Extraction}

The extraction isotherms for all phenols are steep and do not obtain plateau (Fig. 2). Their linear character means that no chemical reaction occurs in the studied systems. It is not possible to load the organic phase to maximum capacity because of the limited solubility of the studied phenols in water (e.g.: 2,4-dichlorophenol). The isotherms of phenol and 4-chlorophenol extracted with Cyanex 923 in octane or toluene differ significantly. 4-chlorophenol is better extracted with Cyanex in toluene, while phenol is transferred with this organic phase significantly weaker. 


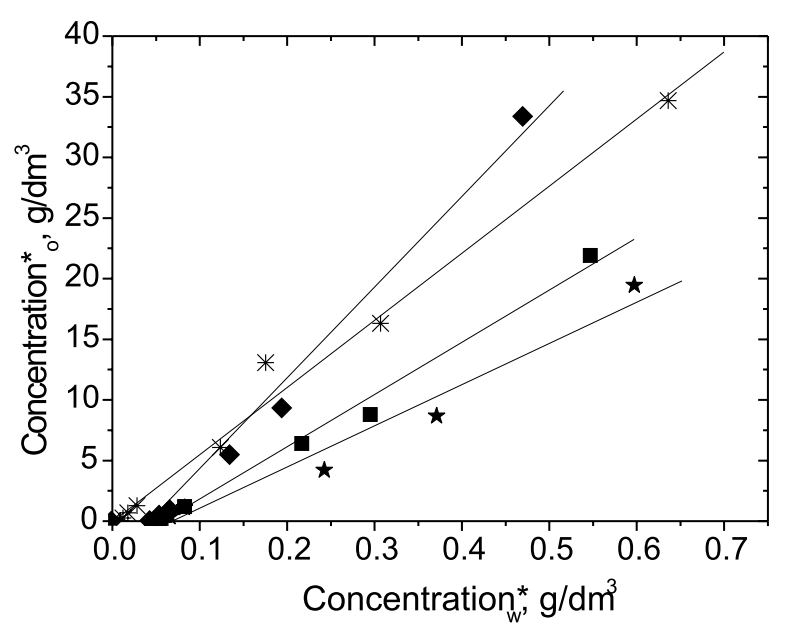

PC

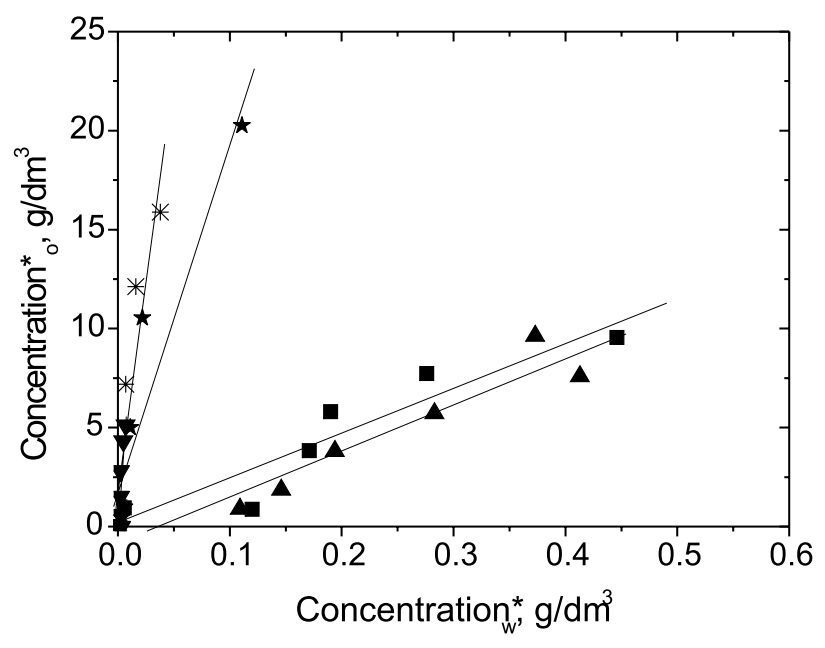

Cyanex 923 in octane

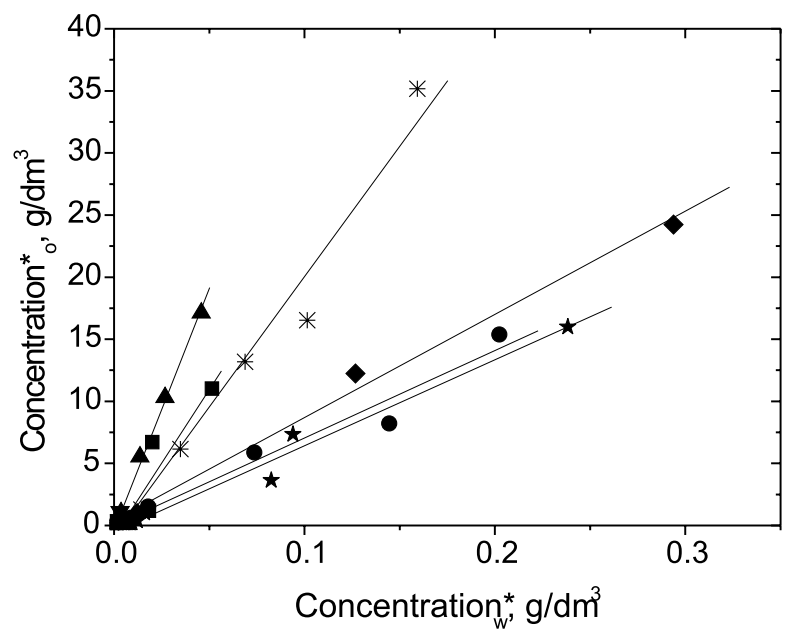

$\mathrm{BC}$

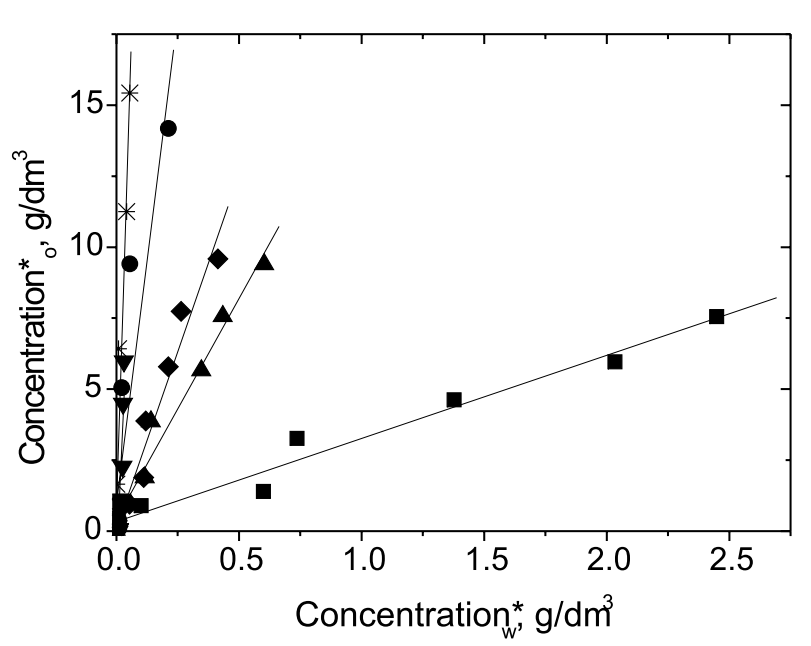

Cyanex 923 in toluene

Figure 2. Isotherms of phenol $(\boldsymbol{\square})$, 4-chlorophenol $(\boldsymbol{\Delta})$, 2,4-dichlorophenol $(\boldsymbol{\nabla})$, 4-fluorophenol $(\boldsymbol{\nabla})$, 4-nitrophenol $(\boldsymbol{*})$, 4methylphenol $(\downarrow)$, 4-methoxyphenol $(\mathbf{O})$ extraction with various organic phases (Aqueous feed: $0.01-22 \mathrm{~g} / \mathrm{dm}^{3} \mathrm{of}$ phenols)

It is possible to remove significant amounts of phenols from the aqueous phase. $\mathrm{BC}$ is the most efficient organic phase because it transfers the greatest amounts of phenols to the organic phase resulting in small phenol content in the raffinate $\left(\max .0 .28 \mathrm{~g} / \mathrm{dm}^{3}\right)$. Some differences between the diluents of Cyanex 923 are noticed. Cyanex 923 in toluene extracts efficiently most phenols except for phenol, while in octane decrease in phenol and 4-chlorophenol extraction is observed.

Extraction properties of the extractants are defined by the distribution ratio of phenols between the organic and the aqueous phase (D), and by extraction efficiency (E) and as shown in Fig. 3. The highest E (between $97-$ $100 \%)$ and $\log \mathrm{D}(1.5-2.5)$ of all phenols are observed when $\mathrm{BC}$ is applied as an extractant. PC enables to remove $85-97 \%$ of phenols, compared with Cyanex 923 in both diluents (between 90 and $99 \%$ ). BC seems to be a more effective extractant than PC and 0.1 M Cyanex 923. Moreover, problems with phase separation and high water content in the organic phase are the main drawback of PC. Therefore it is not recommended to apply PC for extraction of phenols. The solubility of the organic solvent in water is one of the most important parameters in solvent extraction and it should be as low as possible. The more carbon atoms in the alkylene carbonate, the lower the solubility of the compound in water. The difference between propylene and butylene carbonates is approximately three-fold ${ }^{11}$. The same concerns butylene and pentylene carbonates. As pentylene carbonate is not on offer now, BC seems to be the best reagent regarding the solubility in water and it is chosen for the current studies. Extraction of phenols with $\mathrm{BC}$ increases in the following order: phenol $<4$-methylphenol $<$ 4-fluorophenol $<$ 4-methoxyphenol $<4$-nitrophenol $<2$,4-dichlorophenol $<4$-chlorophenol. Whilst for Cyanex 923 in octane the order changes: 4-chlorophenol $<$ phenol $<4$-nitrophenol = 4-methylphenol = 2,4-dichlorophenol. Comparison between Cyanex 923 in octane and toluene indicate Cyanex in toluene as less efficient for phenol extraction (90\%). However, both organic phases transport more than $90 \%$ of phenols studied.

The acidity of phenols is represented by $\mathrm{pK}_{\mathrm{a}}$ shown in Table 1. However, increase in their extraction is consistent rather with the increase in hydrophobicity of these phenols, measured as octanol/water partition coefficient $\left(\log \mathrm{P}_{\mathrm{o} / \mathrm{w}}\right)$, shown also in Table 1 . High recovery of the 

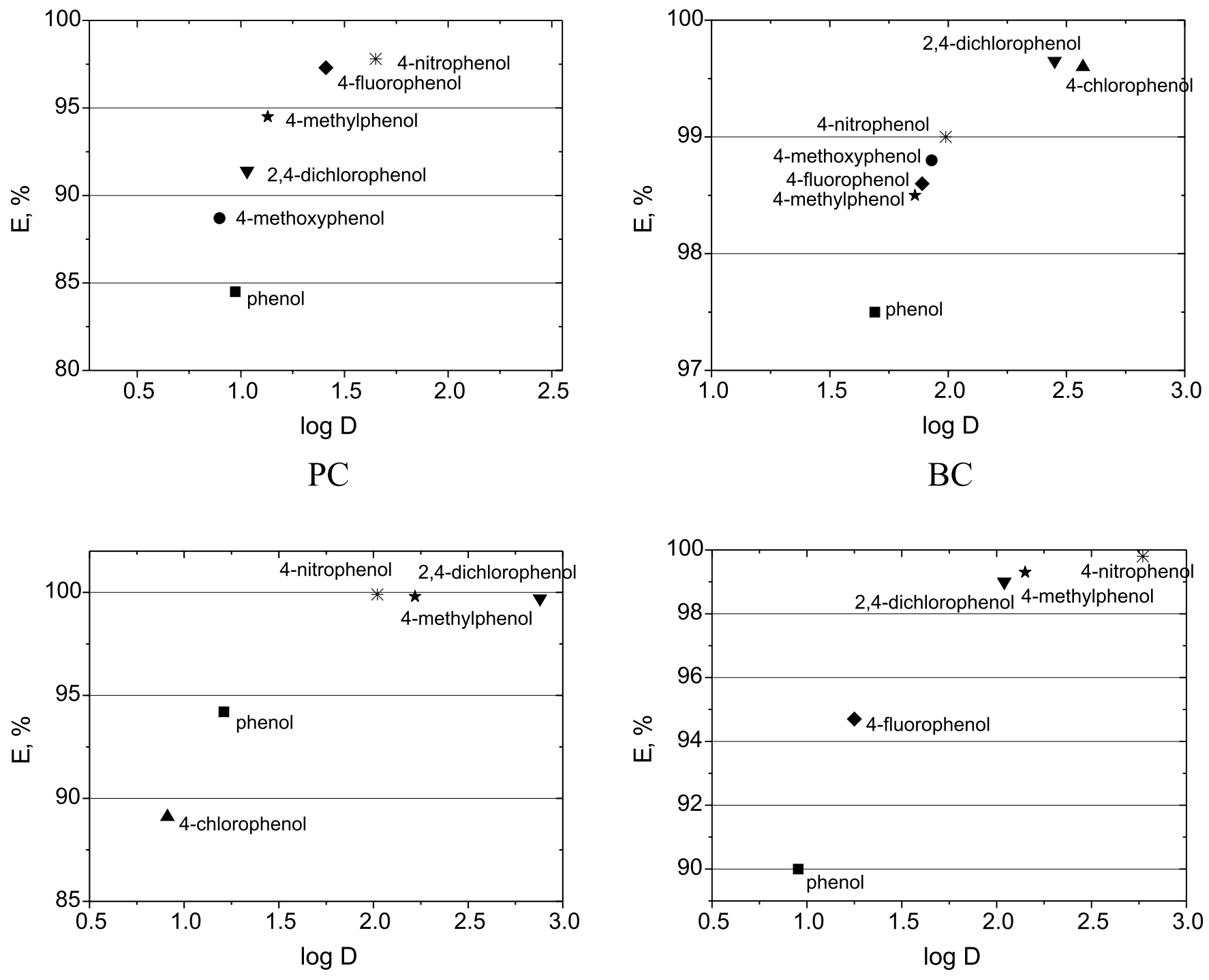

Cyanex 923 in octane

Cyanex 923 in toluene

Figure 3. Extraction parameters of selected phenols for Cyanex 923, PC or BC as extractants (Aqueous feed: $1 \mathrm{~g} / \mathrm{dm}^{3}$ of phenol)

Table 1. $\mathrm{pK}_{\mathrm{a}}$ and $\log \mathrm{P}_{\mathrm{o} / \mathrm{w}}$ for the phenols studied

\begin{tabular}{|l|c|c|}
\hline Type of phenol & $\mathrm{p} K_{a}$ & $\log P_{o / w}$ \\
\hline Phenol & 9.92 & 1.47 \\
4-methoxyphenol & 9.48 & 1.58 \\
4-fluorophenol & 9.60 & 1.62 \\
4-nitrophenol & 7.23 & 1.91 \\
4-methylphenol & 10.28 & 1.97 \\
4-chlorophenol & 9.02 & 2.39 \\
2,4-dichlorophenol & 7.87 & 3.06 \\
\hline
\end{tabular}

phenols with the presented extractants can be explained by the formation of a hydrogen bond between the hydroxyl group of phenols and the oxygen atom of the carbonate group. Additional oxygen atoms in BC seem to play an important role enhancing the extraction of phenols compared with Cyanex 923. Thus, BC can be stated as a prospective extractant due to very well extractive properties and its environmental friendly features.

Enhancement in the extraction of phenols is observed in the presence of an electrolyte $(1 \mathrm{M} \mathrm{NaCl})$ as a result of salting-out effect. As it is shown in Table 2, the extraction efficiency is very high both without $\mathrm{NaCl}(97.7-$ 99.6\%) and in the presence of $\mathrm{NaCl}(98.2-99.7 \%)$ for all the phenols studied, and increases with increasing phenol hydrophobicity. The effect of electrolyte presence is more distinct for distribution ratio values. $D$ of
Table 2. Efficiency of various phenols extraction and partition coefficient for extraction with BC (for feed concentration of phenols: $1 \mathrm{~g} / \mathrm{dm}^{3}$ )

\begin{tabular}{|l|c|c|c|}
\hline Type of phenol & Content of $\mathrm{NaCl}, \mathrm{M}$ & $\mathrm{E}, \%$ & $\mathrm{D}$ \\
\hline \multirow{2}{*}{ Phenol } & 0 & 97.8 & 45 \\
& 1 & 98.2 & 60 \\
\hline \multirow{2}{*}{ 4-methoxyphenol } & 0 & 97.9 & 40 \\
& 1 & 98.8 & 85 \\
\hline \multirow{2}{*}{ 4-fluorophenol } & 0 & 98.6 & 80 \\
& 1 & 98.8 & 90 \\
\hline \multirow{2}{*}{ 4-nitrophenol } & 0 & 97.7 & 40 \\
& 1 & 98.9 & 90 \\
\hline \multirow{2}{*}{ 4-methylphenol } & 0 & 98.5 & 70 \\
& 1 & 98.8 & 90 \\
\multirow{2}{*}{ 4-chlorophenol } & 0 & 99.5 & 200 \\
& 1 & 99.6 & 300 \\
\hline \multirow{2}{*}{ 2,4-dichlorophenol } & 0 & 99.6 & 300 \\
& 1 & 99.7 & 400 \\
\hline
\end{tabular}

4-methoxyphenol and 4-nitrophenol in the presence of electrolyte is twice as high (85; 90, respectively) as without $\mathrm{NaCl}$ (40, in both cases). The highest $\mathrm{D}$ values are obtained for 4-chlorophenol $(200 ; 300)$ and 2,4dichlorophenol $(300 ; 400)$ both with and without $\mathrm{NaCl}$.

Contribution of ionic form of 4-nitrophenol, 2,4dichlorophenol and 4-methylphenol in the aqueous phase 


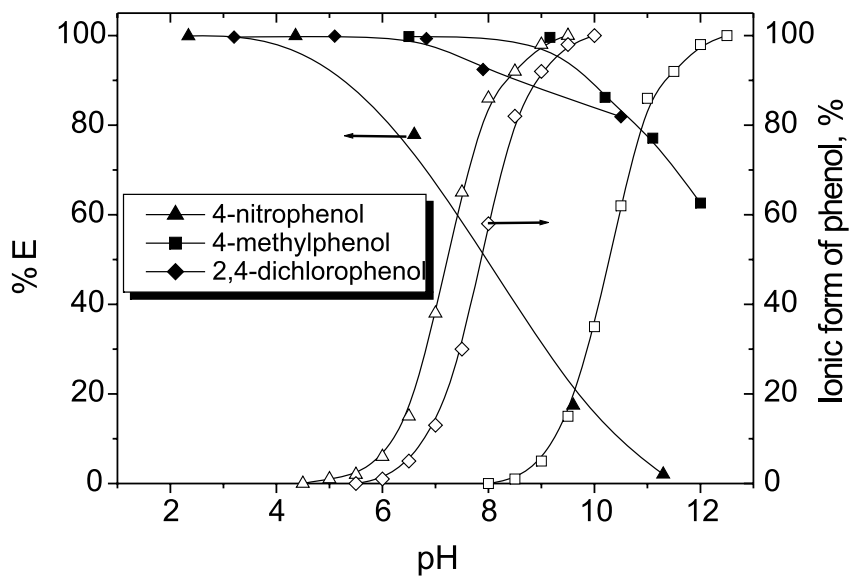

Figure 4. Effect of $\mathrm{pH}$ change and contribution of ionic form of phenol on extraction efficiency of selected phenols with 0.1 M Cyanex 923

in the range of $\mathrm{pH}$ and its effect on extraction efficiency with 0.1 M Cyanex 923 in octane is shown in Fig. 4. The change in $\mathrm{pH}$ affects the extraction of all the phenols studied. The convenient $\mathrm{pH}$ for phenols extraction is limited to the values lower than $\mathrm{pK}_{\mathrm{a}}$ (Table 1). The effect of $\mathrm{pH}$ is the most significant for 4-nitrophenol, which is extracted the most efficiently at $\mathrm{pH} 2-4$. Above $\mathrm{pH} 6$ the extraction efficiency decreases significantly down to $60 \%$, and decreases with further increase of $\mathrm{pH}$. 4-nitrophenol is not extracted above $\mathrm{pH} 11$. The higher $\mathrm{pH}$ the greater contribution of ionic form of 4-nitrophenol $(60 \%$ at $\mathrm{pH}$ 6 ), which is extracted less efficiently than the neutral form. Extraction of 2,4-dichlorophenol and 4methylphenol is weaker influenced by $\mathrm{pH}$ increase. At $\mathrm{pH}$ 10 extraction of 4-methylphenol decreases to $60 \%$, while a slight decrease in extraction is noticed for 2,4dichlorophenol above $\mathrm{pH} 11$. The observations confirm that a non-ionic form is preferred during the extraction with the studied organic phases.

High improvement in extraction properties for alkylene carbonates (particularly BC) can be attributed to the presence of oxygen atom of carbonate group that can form hydrogen bonds with phenols. The linearity of the isotherms presented in Fig. 2 indicates that no other reactions (e.g., association, dissociation) occur in the system except for the reaction of extraction. The mechanism of the extraction both with Cyanex 923 and alkylene carbonates seems to be typical for solvating extractants (S) and runs according to the following reaction: $\mathrm{PhOH}_{(w)}+S_{(o)} \Leftrightarrow(\mathrm{PhOH} \cdot \mathrm{S})_{(o)}$.

$\mathrm{BC}$ is more efficient than PC and Cyanex 923. The drawback of $\mathrm{PC}$ is the formation of emulsions, problems with phase separation and a high content of water in the organic phase. PC is the most hydrophilic among the extractants studied, that results in high water content (more than 9\%) after the extraction (Fig. 5). Hydrophobicity of alkylene carbonates increases with increasing alkyl chain

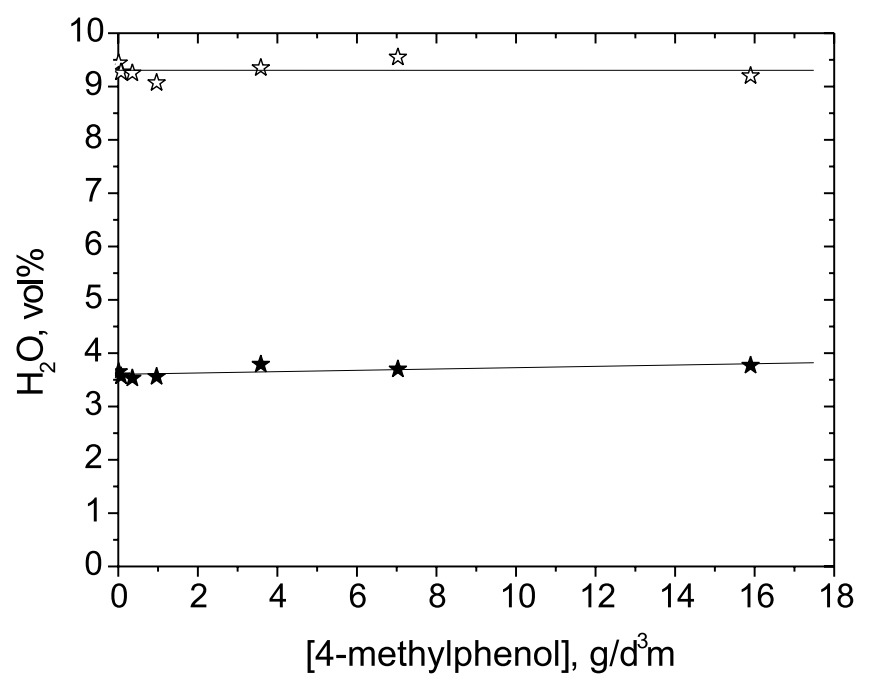

Figure 5. Water content in BC ( $\downarrow)$ and PC ( $\downarrow$ ) after extraction of 4-methylphenol

length $-\mathrm{BC}$ after the extraction contains almost three times less water than PC (3.5\%).

\section{Stripping}

Stripping from the loaded organic phases was carried out with $0.1 \mathrm{M} \mathrm{NaOH}$, and the efficiency of exemplary phenols is presented in Table 3. In one step more than $80 \%$ of 4-nitrophenol, almost $60 \%$ of 2,4-dichlorophenol and more than $30 \%$ of 4-methylphenol is stripped from loaded Cyanex 923 in octane. Opposite results are observed for Cyanex 923 in toluene. Stripping efficiency increases in the following order: 4-nitrophenol $(4.1 \%)$ $<2$,4-dichlorophenol $(63.7 \%)<4$-methylphenol $(75.3 \%)$. It means that 2,4-dichlorophenol and 4-methylphenol could be stripped completely from the loaded Cyanex 923 in octane or toluene at least in two stripping steps. Stripping from alkylene carbonates is inefficient $(0.85-16 \%)$ probably as a result of carbonate hydrolysis in the contact with $\mathrm{NaOH}$. In the case of propylene carbonate formation of emulsion is observed, which eliminates it form the application in extraction.

\section{CONCLUSIONS}

1. Compared with solvating extractant Cyanex 923, BC is a more effective extractant for all the phenols studied. It enables a removal of more than $95 \%$ phenol up to 100\% 4-chlorophenol.

2. The main disadvantage of butylene carbonate is its low stripping efficiency with $\mathrm{NaOH}$. It should be carried out in several steps, but it is threatened with hydrolysis or another stripping solution should be applied.

3. The ability of phenols to be transferred to the organic phase is influenced by their increasing hydrophobicity. The smaller affinity to the aqueous phase the better extraction to the organic phase. Additionally, extraction of phenols strongly depends on the presence of their non-

Table 3. Stripping efficiency $(\mathrm{R})$ of selected phenols from loaded organic phases with $0.1 \mathrm{M} \mathrm{NaOH}$ (organic phase loaded with phenol up to $\sim 6 \mathrm{~g} / \mathrm{dm}^{3}$ )

\begin{tabular}{|l|c|c|c|}
\hline Type of phenol & Cyanex 923 in octane & Cyanex 923 in toluene & BC \\
\hline 4-NITROPHENOL & 80.9 & 4.1 & 16.0 \\
\hline 2,4-dichlorophenol & 58.5 & 63.7 & 0.85 \\
\hline 4-methylphenol & 33.3 & 4.5 & 75.3 \\
\hline
\end{tabular}


ionic form, and requires strict $\mathrm{pH}$ control of the aqueous feed.

4. The improvement in the extraction properties for alkylene carbonates can be attributed to the presence of three oxygen atoms of carbonate group that forms hydrogen bonds with phenols.

5. Propylene carbonate is a not efficient extractant because it forms emulsions and transfers great amounts of water.

6. Hydrophobicity of alkylene carbonates increases with increasing alkyl chain length - BC after the extraction contains almost three times less water than PC.

\section{ACKNOWLEDGMENT}

The work was supported by the 32/270/10-BW grant.

\section{LITERATURE CITED}

1. Lin, S.H. \& Juang, R.S. (2009). Adsorption of Phenol and Its Derivatives from Water Using Synthetic Resins and Low-Cost Natural Adsorbents: A Review. J. Environ. Manage. 90, 1336 - 1349. DOI: 10.1016/j.jenvman.2008.09.003.

2. Alkaram, U.F., Mukhlis, A.A. \& Al-Dujaili, A.H. (2009). The Removal of Phenol from Aqueous Solutions by Adsorption Using Surfactant-Modified Bentonite and Kaolinite. J. Hazard. Mater. 169, 324 - 332. DOI: 10.1016/ j.jhazmat.2009.03.153.

3. Caetano, M., Valderrama, C., Farran, A. \& Cortina, J.L. (2009). Phenol Removal from Aqueous Solution by Adsorption and Ion Exchange Mechanisms onto Polymeric Resins. J. Colloid Interf. Sci. 338, 402 - 409. DOI: 10.1016/ j.jcis.2009.06.062.

4. Agarwal, S., Ferreira, A.E., Reis, M.T.A., Ismael, M.R.C., Ferreira, L.M., Machado, R.M. \& Carvalho, J.M.R. (2009). A Study on a Combined Process for the Treatment of Phenolic Resin Plant Effluents. J. Hazard. Mater. 169, 659 - 666. DOI: 10.1016/j.jhazmat.2009.03.139.

5. Kujawski, W., Warszawski, A., Ratajczak, W., Porębski, T., Capata, W. \& Ostrowska, I. (2004). Removal of Phenol from Wastewater by Different Separation Techniques. Desalination 163, 287 - 296. DOI: 10.1016/S0011-9164(04)90202-0.

6. Cichy, W. \& Szymanowski, J. (2002). Recovery of Phenol from Aqueous Streams in Hollow Fiber Modules. Environ. Sci. Technol. 36, 2088 - 2093. DOI: 10.1021/es010910w.

7. Busca, G., Berardinelli, S., Resini, C. \& Arrighi, L. (2008). Technologies for the Removal of Phenol from Fluid Streams: A Short Review of Recent Developments. J. Hazard. Mater. 160, 265 - 288. DOI: 10.1016/j.jhazmat.2008.03.045.

8. Olejniczak, J., Staniewski, J. \& Szymanowski, J. (2005). Extraction of phenols and phenyl acetates with diethyl carbonate. Anal. Chim. Acta, 535, 251 - 257. DOI: 10.1016/ j.aca.2004.11.080.

9. Lyman, W.J. (1990). Handbook of Chemical Property Estimation Methods. Washington, USA: ACS.

10. Huntsman, Jeffsol ${ }^{\circledR}$ Alkylene Carbonates in Personal Care, Technical Bulletin, 2003. Retrieved January 2010, from: http://www.huntsman.com/performance_chemicals/Media/ JEFFSOL_Alkylene_Carbonates_(brochure).pdf

11. Regel-Rosocka, M. \& Szymanowski, J. (2005). Direct Yellow and Methylene Blue Liquid-Liquid Extraction with Alkylene Carbonates. Chemosphere 60, 1151 - 1156. DOI: 10.1016/j.chemosphere.2005.01.019.

12. Dziwinski, E. \& Szymanowski, J. (1998). Composition of Cyanex 923, Cyanex 925, Cyanex 921 and TOPO. Solvent Extr. Ion Exc. 16(6), 1515 - 1525. DOI: 10.1080/07366299808934592. 